Article

\title{
Versatile Poly(Diallyl Dimethyl Ammonium Chloride)-Layered Nanocomposites for Removal of Cesium in Water Purification
}

\author{
Sung-Chan Jang ${ }^{1,2,+}$, Sung-Min Kang ${ }^{2,+}$, Gi Yong Kim ${ }^{1,3,+} \mathbb{D}^{\mathbb{B}}$, Muruganantham Rethinasabapathy ${ }^{2}$, \\ Yuvaraj Haldorai ${ }^{4}$, Ilsong Lee ${ }^{1,2}$, Young-Kyu Han ${ }^{4}$, Joanna C. Renshaw ${ }^{5, *}$, Changhyun Roh ${ }^{1,6, *}$ (i) \\ and Yun Suk Huh ${ }^{2, *}$ \\ 1 Biotechnology Research Division, Advanced Radiation Technology Institute (ARTI), Korea Atomic Energy \\ Research Institute (KAERI), 29, Geumgu-gil, Jeongeup-si, Jeonbuk 56212, Korea; scjscjsc@gmail.com (S.-C.J.); \\ kgyong@kaeri.re.kr (G.Y.K.); islee2046@gmail.com (I.L.) \\ 2 Department of Biological Engineering, Biohybrid Systems Research Center (BSRC), Inha University, 100, \\ Inha-ro, Incheon 22212, Korea; sungmin.kang21@gmail.com (S.-M.K.); rmaannauniv@gmail.com (M.R.) \\ 3 Radwaste Management Center, Korea Atomic Energy Research Institute (KAERI), 989, Daedeok-daero, \\ Daejeon 34057, Korea \\ 4 Department of Energy and Materials Engineering, Dongguk University-Seoul, 30, Pildong-ro 1-gil, \\ Seoul 04620, Korea; yuvraj_PD@yahoo.co.in (Y.H.); ykhan1972@gmail.com (Y.-K.H.) \\ 5 Department of Civil and Environmental Engineering, University of Strathclyde, James Weir Building, \\ 75 Montrose St, Glasgow G1 1XJ, UK \\ 6 Radiation Biotechnology and Applied Radioisotope Science, University of Science and Technology (UST), \\ 217, Gajeong-ro, Daejeon 34113, Korea \\ * Correspondence: Joanna.renshaw@strath.ac.uk (J.C.R.); chroh@kaeri.re.kr (C.R.); \\ yunsuk.huh@inha.ac.kr (Y.S.H.); Tel.: +82-63-570-3133 (C.R.); Fax: +82-63-570-3139 (C.R.) \\ + These authors contributed equally to this work.
}

Received: 13 April 2018; Accepted: 8 June 2018; Published: 12 June 2018

\begin{abstract}
In this work, we elucidate polymer-layered hollow Prussian blue-coated magnetic nanocomposites as an adsorbent to remove radioactive cesium from environmentally contaminated water. To do this, $\mathrm{Fe}_{3} \mathrm{O}_{4}$ nanoparticles prepared using a coprecipitation method were thickly covered with a layer of cationic polymer to attach hollow Prussian blue through a self-assembly process. The as-synthesized adsorbent was confirmed through various analytical techniques. The adsorbent showed a high surface area $\left(166.16 \mathrm{~m}^{2} / \mathrm{g}\right)$ with an excellent cesium adsorbent capacity and removal efficiency of $32.8 \mathrm{mg} / \mathrm{g}$ and $99.69 \%$, respectively. Moreover, the superparamagnetism allows effective recovery of the adsorbent using an external magnetic field after the adsorption process. Therefore, the magnetic adsorbent with a high adsorption efficiency and convenient recovery is expected to be effectively used for rapid remediation of radioactive contamination.
\end{abstract}

Keywords: Prussian blue; magnetic nanoparticles; adsorbent; cesium; magnetic separation

\section{Introduction}

Multifunctional polymer nanocomposites cover a very wide range of polymer matrices and hybrid polymer materials for their industrial applications [1,2].

The release of radionuclides, including fission products, from the long-term use of nuclear fuels and occasional nuclear disasters, such as at Chernobyl and the Fukushima Daiichi nuclear power plants, is an emerging issue [1-4]. In particular, radioactive cesium $\left({ }^{137} \mathrm{Cs}\right)$, a fission product formed in nuclear reactors, is a problematic contaminant due to its high radioactivity, relatively long half-life (30.2 years), and bioavailability [5-7]. ${ }^{137} \mathrm{Cs}$ can cause a number of significant health problems, including carcinoma 
of the kidney, liver, renal functions, and bladder as well as cardiovascular disease and gastrointestinal distress [8-11].

Various materials have been investigated for the removal of ${ }^{137} \mathrm{Cs}$, including polymers, zeolites, clay minerals, silica, and other nanomaterials [12-14]. However, these are unsuitable for column loading and are not easy to separate from aqueous solutions by filtration or centrifugation after cesium adsorption [4].

Prussian blue $(\mathrm{PB})$ is a low-cost adsorbent with a strong affinity and high selectivity for cesium. It is also a U.S. Food and Drug Administration (FDA) approved drug employed for the handling of radioactive exposure [15] and has the potential for effective remediation of cesium. There are many reports on PB-based composites for the removal of radioactive cesium, such as PB/graphene foam [16], $\mathrm{PB} /$ silica [7,17], PB/glass pores [18], and PB/Alginate bead [19]. However, all of these adsorbents are either hard to synthesize or too expensive for large-scale applications. Magnetic separation, which has been used for the removal of cesium, is a fast, easy, and efficient method to recover an adsorbent. Combining PB and magnetic particles for the removal of radioactive cesium has many advantages. $\mathrm{PB}$ can selectively remove ${ }^{137} \mathrm{Cs}$ and the adsorbent can be easily separated from environmentally contaminated water using an external magnet.

In the present study, a novel nanocomposite material composed of $\mathrm{PB} / \mathrm{poly}$ (diallyl dimethyl ammonium chloride) (PDDA)-coated magnetic particles $\left(\mathrm{Fe}_{3} \mathrm{O}_{4}\right)$ was synthesized for efficient adsorption of ${ }^{137} \mathrm{Cs}$ from an aqueous solution. The synthesized adsorbent was characterized using different techniques (e.g., XRD, FTIR, and TEM) and the effect of adsorbent dosage and $\mathrm{pH}$ on the removal efficiency of ${ }^{137} \mathrm{Cs}$ was investigated. The developed adsorbent was recovered easily using an external magnet and showed a high adsorption capacity that can help solve the difficulty of recovering existing adsorbent materials.

\section{Materials and Methods}

Materials: Iron (II) chloride tetrahydrate $\left(\mathrm{FeCl}_{2} \cdot 4 \mathrm{H}_{2} \mathrm{O}\right)$, Iron (III) chloride hexahydrate $\left(\mathrm{FeCl}_{3} \cdot 6 \mathrm{H}_{2} \mathrm{O}\right)$, potassium hexacyanoferrate (III) trihydrate $\left(\mathrm{K}_{3}\left[\mathrm{Fe}(\mathrm{CN})_{6}\right] \cdot 3 \mathrm{H}_{2} \mathrm{O}\right)$, PDDA solution (20 wt \%, MW 400,000 500,000), hydrochloric acid $(\mathrm{HCl})$ and ammonium hydroxide $\left(\mathrm{NH}_{4} \mathrm{OH}\right)$, polyvinylpyrrolidone (PVP, MW $=40,000)$ were purchased from Sigma-Aldrich, Korea. A standard cesium solution (1000 ppm) was purchased from Kanto Chemical Co. Inc. (Tokyo, Japan). All chemicals used in this study were of analytical reagent grade. Deionized (DI) water was used in this study. Additionally, ${ }^{137}$ Cs solution was provided from the Korea Atomic Energy Research Institute (KAERI), Daejeon, Korea.

\subsection{Characterization}

A transmission electron microscopy (TEM) analysis was performed using a Tecnai G2 (FEI, Eindhoven, The Netherland) microscope at an accelerating voltage of $200 \mathrm{kV}$ and equipped with an energy dispersive spectrometer (EDS, Oxford Instruments, Oxford, UK). Fourier-transform infrared spectroscopy (FTIR) was analyzed using a Jasco-6600 spectrometer (JASCO, Weinheim, Germany). The hydrodynamic diameter and zeta potential measurements were carried out using a dynamic light scattering measurement collected on a Zetasizer Nano ZS (Malvern, UK). The X-ray diffraction (XRD) patterns were mainly collected using a Bruker D2 PHASER (Hamburg, Germany) diffractometer with $\mathrm{Cu}$ K(alpha) radiation. The Brunauer-Emmett-Teller (BET) surface area and average pore diameter were obtained from the $\mathrm{N}_{2}$ adsorption/desorption isotherm using a fully automatic physisorption analyzer (ASAP 2020, Micromeritics Instrument Corp., Norcross, GA, USA).

\subsection{Preparation of Magnetic PDDA@Fe $\mathrm{O}_{4}$}

PDDA-coated magnetic particles were prepared according to a previous report [20]. A solution (20 mL) containing $\mathrm{FeCl}_{2} \cdot 4 \mathrm{H}_{2} \mathrm{O}(0.8 \mathrm{~g}), \mathrm{FeCl}_{3} \cdot 6 \mathrm{H}_{2} \mathrm{O}(2.16 \mathrm{~g})$, and PDDA $(1.0 \%, v / v)$ was deoxygenated by bubbling with nitrogen gas for $10 \mathrm{~min}$, followed by heating to $80^{\circ} \mathrm{C}$. Subsequently, $10 \mathrm{~mL}$ of $\%$ $\mathrm{NH}_{4} \mathrm{OH}$ was added quickly to the heated solution, which was left to stir for another $1 \mathrm{~h}$. After cooling 
to room temperature, the obtained PDDA-coated $\mathrm{Fe}_{3} \mathrm{O}_{4}$ nanoparticles (NPs) were isolated using a magnet field and washed three times with deionized water. Finally, the nanoparticles were dried at comfortable room temperature.

\subsection{Synthesis of Mesocrystal and Hollow PB Particles}

For the synthesis of mesocrystal Prussian blue (MPB) [21], $3 \mathrm{~g}$ of PVP and $131.7 \mathrm{mg}$ of $\mathrm{K}_{3}\left[\mathrm{Fe}(\mathrm{CN})_{6}\right] \cdot 3 \mathrm{H}_{2} \mathrm{O}$ were added into a $0.1 \mathrm{M} \mathrm{HCl}$ solution $(40 \mathrm{~mL})$ under magnetic stirring, and a clear solution was obtained after $1 \mathrm{~h}$. The solution was then heated in an oven at $80{ }^{\circ} \mathrm{C}$ for $20 \mathrm{~h}$. The precipitate formed was then collected through centrifugation, washed with distilled water and ethanol two times, and dried at room temperature for $12 \mathrm{~h}$. Hollow Prussian blue (HPB) particles were synthesized by controlled chemical etching of MPB particles [21]. In brief, $20 \mathrm{mg}$ of MPB and $100 \mathrm{mg}$ PVP were added to a $1.0 \mathrm{M} \mathrm{HCl}$ solution $(20 \mathrm{~mL})$ under magnetic stirring. After $1 \mathrm{~h}$, the solution was transferred into a stainless autoclave and heated at $135^{\circ} \mathrm{C}$ for $2.5 \mathrm{~h}$. The HPB particles that were precipitated from the solution were subsequently collected by centrifugation, washed with distilled water and ethanol two times, and then dried at comfortable room temperature for $12 \mathrm{~h}$.

\subsection{Synthesis of PB@PDDA@Fe ${ }_{3} \mathrm{O}_{4}$ Composite}

To synthesize the composite nanoparticles, $1 \mathrm{~g}$ of $\mathrm{PDDA} @ \mathrm{Fe}_{3} \mathrm{O}_{4}$ was mainly dispersed in $10 \mathrm{~mL}$ of distilled water, and $0.01 \mathrm{M} \mathrm{HCl}$ was added to adjust the $\mathrm{pH}$ to 6 . Then, $3 \mathrm{~g}$ of $\mathrm{MPB}$ or HPB particles were added to the above solution and $0.01 \mathrm{M} \mathrm{NaOH}$ was added to adjust the $\mathrm{pH}$ to 6 . The slurry obtained was thoroughly mixed at room temperature in a $50 \mathrm{~mL}$ polypropylene tube. The MPB or HPB particles were attached to the surface of PDDA@ $\mathrm{Fe}_{3} \mathrm{O}_{4}$ due to the electrostatic interaction. The obtained HPB@PDDA@ $\mathrm{Fe}_{3} \mathrm{O}_{4}$ composite was separated from the solution using an external magnet (1.4 teslas) and washed several times with distilled water.

\subsection{Adsorption Experiments}

The adsorption isotherms were investigated using batch experiments with a non-radioactive isotope, ${ }^{133} \mathrm{Cs}$. The initial Cs concentration varied from 1-200 ppm. Adsorbent (10 mg) was added to the Cs solution $(4 \mathrm{~mL})$. After equilibrating for $12 \mathrm{~h}$, the adsorbent was separated by a magnet and the residual $\mathrm{C}$ s concentration in the solution was analyzed by inductively coupled plasma mass spectrometry (ICP-MS, PerkinElmer ELAN6100, SCIEX PerkinElmer, Beaconsfield, UK). A radioactive ${ }^{137} \mathrm{C}$ s adsorption experiment is given in detail in the supporting information. All experiments were conducted 3 to 5 times.

\subsection{Radioactive ${ }^{137}$ Cs Decontamination}

Different amounts of HPB@PDDA@ $\mathrm{Fe}_{3} \mathrm{O}_{4}$ composite $(0.5,2$, or $5 \mathrm{mg})$ were added to $10 \mathrm{~mL}$ of the ${ }^{137} \mathrm{Cs}$ aqueous solution $(100 \mathrm{~Bq} / \mathrm{g})$; the concentrations of PB NPs $/ \mathrm{mL}$ of the ${ }^{137} \mathrm{Cs}$ solution were $0.05,0.2,0.5 \mathrm{mg} / \mathrm{mL}$, respectively. After adsorption of ${ }^{137} \mathrm{Cs}$ for $12 \mathrm{~h}$, the adsorbent was removed using an external magnet. The solution concentrations of the ${ }^{137} \mathrm{C}$ s before and after treatment with the adsorbents were analyzed using a high-purity germanium (HPGe) detector (Canberra Inc., Meriden, CT, USA). In particular, we measured more than 3000 counts per second (cps) in each experiment for $1 \mathrm{~h}$.

\subsection{The Influence of $p H$ on the Removal of ${ }^{137} \mathrm{Cs}$}

The removal of ${ }^{137} \mathrm{Cs}$ as a function of solution $\mathrm{pH}$ ranging from 4-10 was prepared by adjusting the $\mathrm{pH}$ using $\mathrm{HCl}$ and $\mathrm{NH}_{4} \mathrm{OH}$. The initial ${ }^{137} \mathrm{Cs}$ concentration was $100 \mathrm{~Bq} / \mathrm{g}$. All experiments were equilibrated for $12 \mathrm{~h}$ with stirring. The nanocomposite was then separated from the solution using a magnet, and the residual ${ }^{137} \mathrm{C}$ s concentration was measured using a HPGe detector (Canberra Inc., Meriden, CT, USA). 


\section{Results and Discussion}

\subsection{Fabrication of the Magnetic Adsorbent}

Figure 1 shows a schematic representation of the synthesis of PB@PDDA@Fe $\mathrm{O}_{4}$. The PDDA@ $\mathrm{Fe}_{3} \mathrm{O}_{4}$ composite was prepared via a precipitation reaction. The negatively charged PB (MPB or $\mathrm{HPB}$ ) was added in excess to a smaller amount of positively charged PDDA@ $\mathrm{Fe}_{3} \mathrm{O}_{4}$, and the surface area of the positively charged PDDA@Fe $\mathrm{F}_{4}$ was completely covered by negatively charged PB via self-assembly.

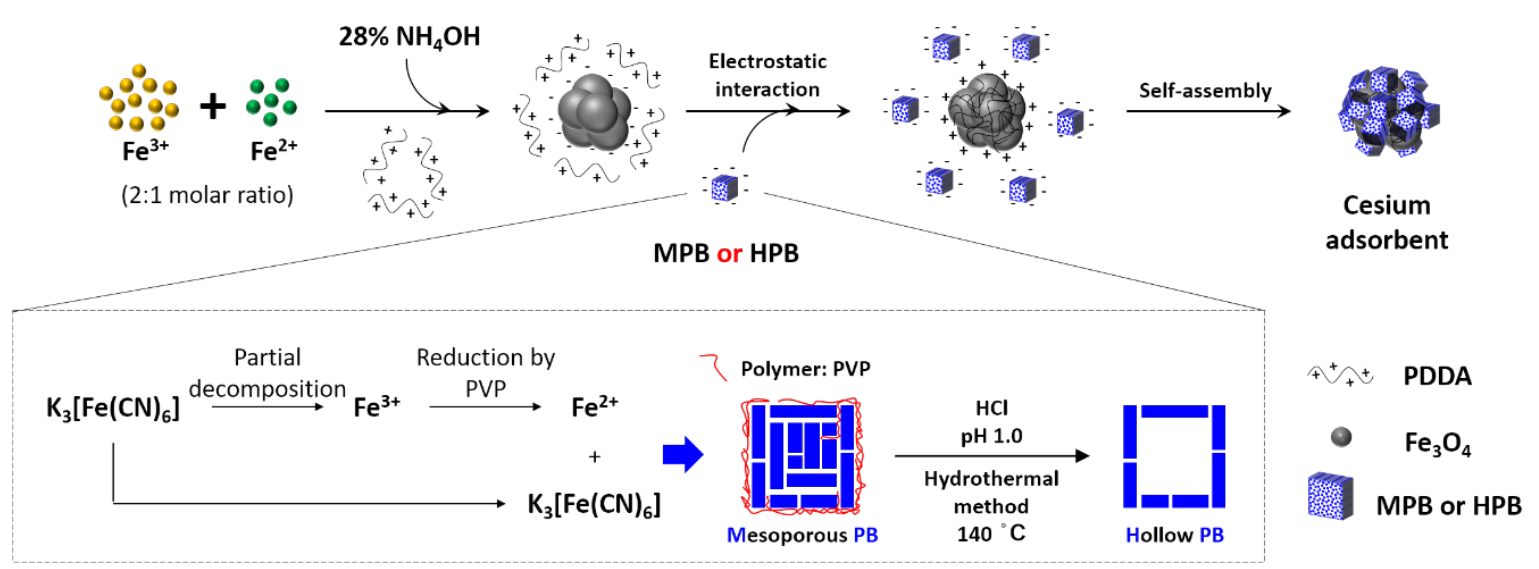

Figure 1. Schematic diagram of the synthesis of hollow Prussian blue (HPB)@ poly(diallyl dimethyl ammonium chloride) (PDDA)@ $\mathrm{Fe}_{3} \mathrm{O}_{4}$ nanocomposites.

The TEM image of the PDDA@ $\mathrm{Fe}_{3} \mathrm{O}_{4}$ composite showed aggregated particles with a mean diameter of 200-300 nm, and the subunits were smaller spherical nanocrystals with a size of about $10 \mathrm{~nm}$ (Figure 2a,b). HRTEM images (Figure 2b) of the subunits and their corresponding fast Fourier transform (FFT) patterns (Figure $2 \mathrm{~b}$ inset) indicated the presence of $\mathrm{Fe}_{3} \mathrm{O}_{4}$; the spacing of the lattice planes were calculated to be $0.25 \mathrm{~nm}$, which corresponds to the families of crystal planes of $\mathrm{Fe}_{3} \mathrm{O}_{4}$. The FFT pattern and spacing of the lattice planes showed exactly the same diffraction patterns compared to $\mathrm{Fe}_{3} \mathrm{O}_{4}$ (Figure S1).

Two forms of PB NPs were used: MPB and HPB. MPB was achieved by direct dissociation of a single-source precursor $\mathrm{K}_{3}\left[\mathrm{Fe}(\mathrm{CN})_{6}\right]$ with $\mathrm{PVP}$ as a capping and reducing agent. The whole reaction was based on the partial decomposition and reduction of $\mathrm{K}_{3}\left[\mathrm{Fe}(\mathrm{CN})_{6}\right]$ in acidic solution with the addition of PVP. $\left[\mathrm{Fe}(\mathrm{CN})_{6}\right]^{3-}$ ions were slowly dissociated into $\mathrm{Fe}^{3+}$ ions in acidic solution and the $\mathrm{Fe}^{3+}$ ions were subsequently reduced into $\mathrm{Fe}^{2+}$ ions by the weak reducer (PVP). Finally, Prussian blue was synthesized through the recrystallization of small particles by the assistance of PVP. MPB was chemically etched with $\mathrm{HCl}$ to create $\mathrm{HPB}$ with interior hollow cavities. The surface of the HPB (Figure S2c,d) was much rougher than MPB (Figure S2a,b) and the particles size was smaller because of chemical etching. When $\mathrm{H}^{+}$ions diffused into the MPB, the local concentration of $\mathrm{H}^{+}$ions in the center part of the MPB was higher than that of the particle surface. The etching rate of Prussian blue in the center became relatively high, thereby reshaping the interior hollow pore. The TEM image of the HPB (Figure 2c) displayed a network of connected particles. The corresponding selected area electron diffraction (SAED) pattern (Figure 2c inset) showed a diffused ring pattern, indicating a polycrystalline nature [22]. Figure 2d,e shows that the HPB particles were successfully decorated onto the surface of the PDDA@Fe $\mathrm{O}_{4}$ composite. The coating of PDDA onto the $\mathrm{Fe}_{3} \mathrm{O}_{4}$ particles provided a positively charged surface, which could combine easily with the HPB nanoparticles because of their electronegative nature (Figure 2e). The EDS spectra (Figure 2f) of a bright field TEM image revealed that the nanocomposite consisted of $\mathrm{Fe}$ and $\mathrm{O}$ in $\mathrm{Fe}_{3} \mathrm{O}_{4}$ area and $\mathrm{Fe}, \mathrm{C}$, and $\mathrm{N}$ in the HPB area (as indicated in Figure 2e). 

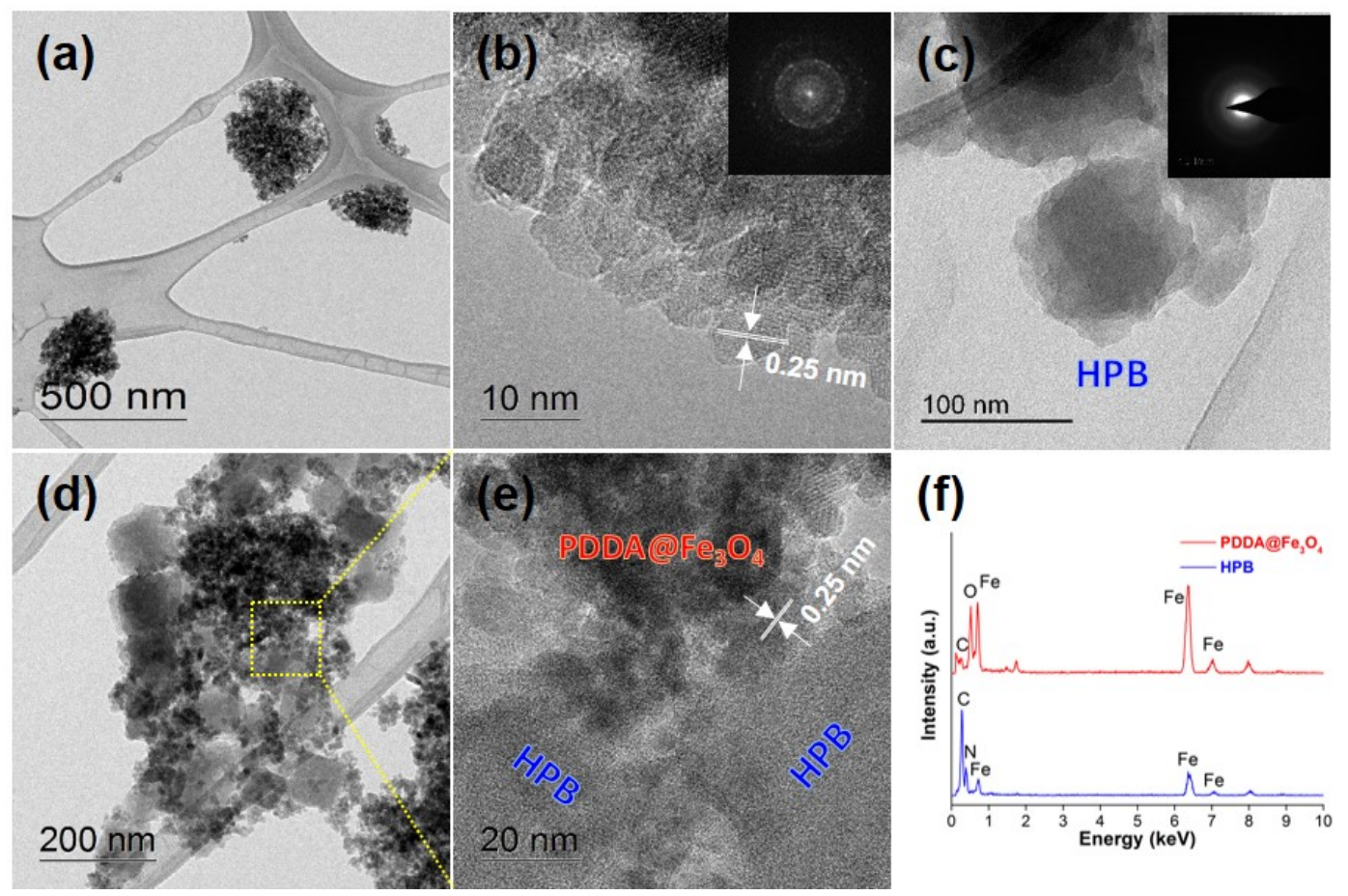

Figure 2. Representative (a) TEM and (b) HRTEM images of PDDA@ $\mathrm{Fe}_{3} \mathrm{O}_{4}$ (The inset shows the fast Fourier transform (FFT) pattern of $\mathrm{Fe}_{3} \mathrm{O}_{4}$ ). (c) HRTEM of HPB nanoparticle (The inset shows selected area electron diffraction (SAED) pattern of HPB). Representative (d) TEM and (e) HRTEM images of the HPB@PDDA@ $\mathrm{Fe}_{3} \mathrm{O}_{4}$ composite, (f) energy dispersive spectrometer (EDS) analysis of HPB and $\mathrm{PDDA} @ \mathrm{Fe}_{3} \mathrm{O}_{4}$ composite.

\subsection{Morphological and Surface Studies}

The surface coating also affected the zeta potential and particle size. The zeta potential values of the $\mathrm{Fe}_{3} \mathrm{O}_{4}, \mathrm{PDDA} @ \mathrm{Fe}_{3} \mathrm{O}_{4}, \mathrm{MPB} @ P D D A @ \mathrm{Fe}_{3} \mathrm{O}_{4}$, and HPB@PDDA@ $\mathrm{Fe}_{3} \mathrm{O}_{4}$ in water were -40, 33, -29 and $-38 \mathrm{mV}$, respectively (Figure $3 \mathrm{a}$ ). Figure $2 \mathrm{~b}$ exhibits a photographic image of an aqueous solution of $\mathrm{Fe}_{3} \mathrm{O}_{4}, \mathrm{PDDA} @ \mathrm{Fe}_{3} \mathrm{O}_{4}, \mathrm{MPB} @ \mathrm{PDDA} @ \mathrm{Fe}_{3} \mathrm{O}_{4}$, and HPB@PDDA@ $\mathrm{Fe}_{3} \mathrm{O}_{4}$. After the reaction between $\mathrm{Fe}_{3} \mathrm{O}_{4}$ and $\mathrm{PB}$, the aqueous solution turned a blue or dark green, indicating $\mathrm{PB}$ on the surface of the magnetic nanoparticles (MNPs).

The FTIR spectra also demonstrated the successful coating of MPB or HPB on the PDDA@Fe3O4 surface (Figure 3c). The absorption bands at 3375-3787 and $1615 \mathrm{~cm}^{-1}$ refer to the $\mathrm{O}-\mathrm{H}$ stretching mode and $\mathrm{H}-\mathrm{O}-\mathrm{H}$ bending mode due to water molecules. The prominent peak intensity of $\mathrm{PB}$ at $2076 \mathrm{~cm}^{-1}$ was observed in HPB@PDDA@Fe3O4 (Figure 3c). The common characteristics of PB were observed from the absorption band at $2076 \mathrm{~cm}^{-1}$ owing to the stretching vibration of the $\mathrm{C} \equiv \mathrm{N}$ group [22]. For the PDDA sample, a strong band at $\sim 3440 \mathrm{~cm}^{-1}$ was attributed mainly to $-\mathrm{NR}_{3}{ }^{+}$ stretching vibration, and the bands around the $3000-2800 \mathrm{~cm}^{-1}$ region were assigned to the $\mathrm{C}-\mathrm{H}$ bending, as shown in Figure 3c [23]. The presence of $\mathrm{Fe}-\mathrm{O}$ bond from $\mathrm{Fe}_{3} \mathrm{O}_{4}$ was also able to be seen at $539 \mathrm{~cm}^{-1}$ for all those samples with $\mathrm{Fe}_{3} \mathrm{O}_{4}$. From the FTIR results, the presence of both $\mathrm{Fe}_{3} \mathrm{O}_{4}$ and $\mathrm{HPB}$ were identified for all samples.

Figure 3d shows the XRD patterns of the samples. For PDDA@Fe3O4, all the diffraction peaks were in good agreement with the face-centered cubic (fcc) structure of magnetite corresponding to (220), (311), (400), (422), (511), and (440) (Figure S3). After HPB coating, a new diffraction peak was shown at $17.4^{\circ}, 24.8^{\circ}$, and $35.3^{\circ}$, which were addressed to (200), (220), and (222) reflections, respectively, of the fcc structure of the HPB nanoparticles. 
(a)

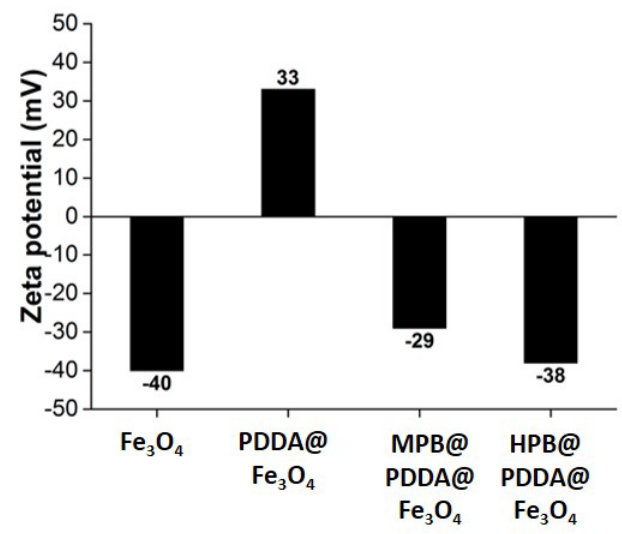

(c)

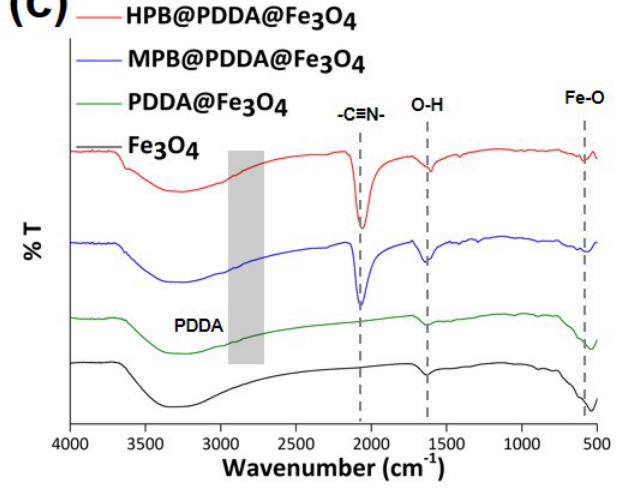

(b)

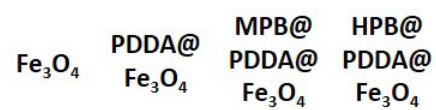

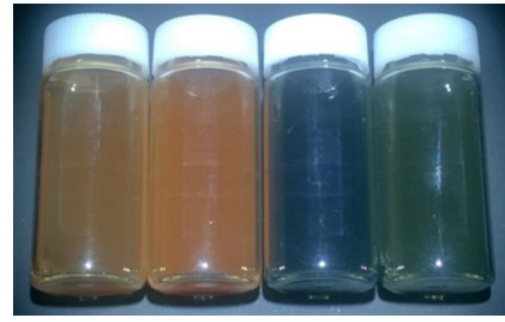

(d)

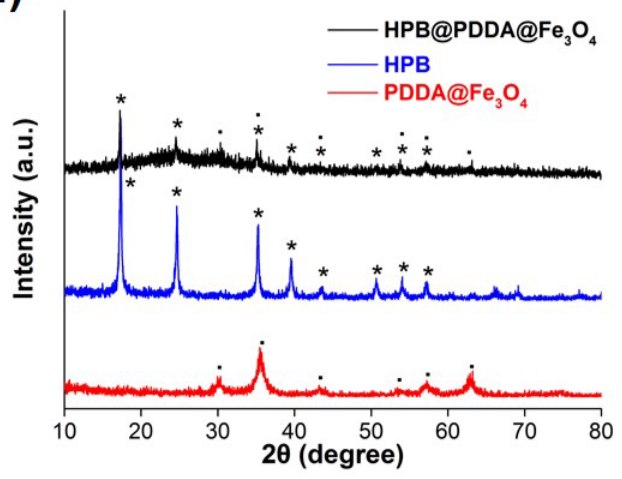

Figure 3. Representative (a) Zeta potential values; (b) Optical image; (c) Fourier-transform infrared spectroscopy (FTIR) spectra; and (d) XRD patterns of $\mathrm{Fe}_{3} \mathrm{O}_{4}, \mathrm{PDDA}_{\mathrm{F}} \mathrm{Fe}_{3} \mathrm{O}_{4}$, mesocrystal Prussian blue (MPB)@PDDA@Fe $\mathrm{O}_{4}$, and $\mathrm{HPB} @ P D D A @ \mathrm{Fe}_{3} \mathrm{O}_{4}$.

Figure 4 shows the $\mathrm{N}_{2}$ adsorption/desorption isotherm and corresponding Barrett-Joyner-Halenda $(\mathrm{BJH})$ pore size distribution curve of the HPB@PDDA@ $\mathrm{Fe}_{3} \mathrm{O}_{4}$ composite. The pore volume of the HPB@PDDA@ $\mathrm{Fe}_{3} \mathrm{O}_{4}$ ranged from 2 to $10 \mathrm{~nm}$ (Figure 4a). The isotherm exhibited that the BET specific surface area of the composite was $166.16 \mathrm{~m}^{2} / \mathrm{g}$ (Figure $4 \mathrm{~b}$ ).

(a)

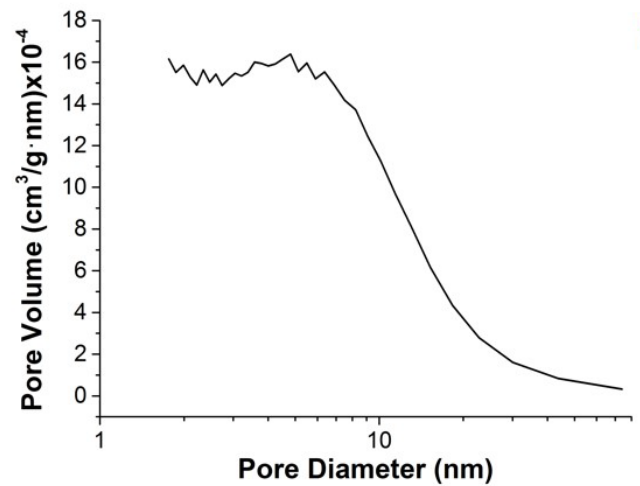

(b)

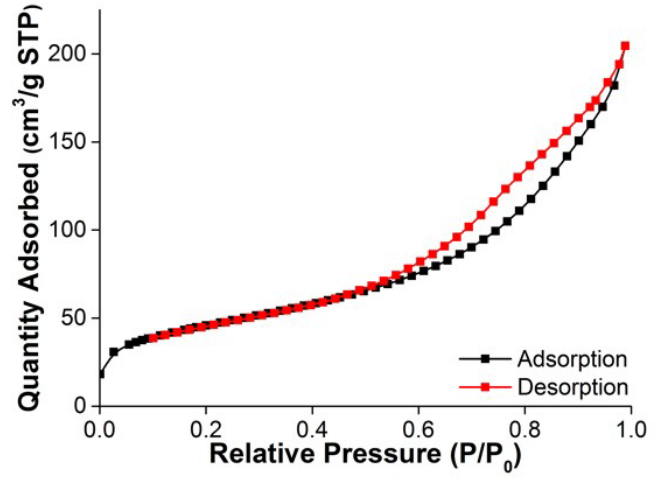

Figure 4. Representative (a) pore size distribution and (b) $\mathrm{N}_{2}$ adsorption/desorption isotherm of the HPB@PDDA@ $\mathrm{Fe}_{3} \mathrm{O}_{4}$ composite. 


\subsection{Performance Evaluation of Cesium Removal}

The uptake of cesium by MPB@PDDA@ $\mathrm{Fe}_{3} \mathrm{O}_{4}$ and HPB@PDDA@ $\mathrm{Fe}_{3} \mathrm{O}_{4}$ composites was investigated in the batch experiments. After $12 \mathrm{~h}$ of contact, the magnetic composites were easily collected to one side of the vial by positioning a magnet against the vial (Figure 5a). The NPs were rapidly separated within $30 \mathrm{~s}$. This demonstrated that the adsorbent could be very easily recovered using an external magnet. The adsorption capacity of magnetic cesium adsorbents was investigated using Langmuir and Freundlich adsorption isotherm models. The Langmuir model [24] is based on the assumption that all active sites are independent and equivalent, and it indicates a monolayer adsorption process for cesium onto the uniformly adsorbent surface. The nonlinear forms of the equation are written as:

$$
q_{e}=q_{\max } \frac{K_{L} C_{e}}{1+K_{L} C_{e}}
$$

where $q_{e}$ and $q_{\max }$ are the equilibrium adsorption capacity and monolayer maximum adsorption capacity $(\mathrm{mg} / \mathrm{g})$, respectively, and $K_{\mathrm{L}}$ is a constant related to the affinity between the adsorbent and the adsorbate. $C_{e}$ is equilibrium concentrations of inactive cesium in the solution. By comparison, the Freundlich adsorption isotherm model [25] is significantly considered to be an empirical equation that describes multilayer adsorption with several types of adsorption sites on the surface of an adsorbent. The model consists of the following equation:

$$
q_{e}=K_{F} C_{e}^{\frac{1}{n}}
$$

where $K_{F}$ and $\mathrm{n}$ are the Freundlich constants relative to the multilayer adsorption capacity. The experimental data of HPB@PDDA@ $\mathrm{Fe}_{3} \mathrm{O}_{4}$ and MPB@PDDA@ $\mathrm{Fe}_{3} \mathrm{O}_{4}$ composites were a better fit to the Langmuir model $\left(R^{2}=0.91\right.$ and 0.90 , respectively) than the Freundlich model $\left(R^{2}=0.79\right.$ and 0.86, respectively). The MPB@PDDA@ $\mathrm{Fe}_{3} \mathrm{O}_{4}$ and HPB@PDDA@ $\mathrm{Fe}_{3} \mathrm{O}_{4}$ possessed a $q_{\max }$ of 25.6 and $32.8 \mathrm{mg} / \mathrm{g}$, respectively (Figure $5 \mathrm{~b}$ ).

\section{(a)}

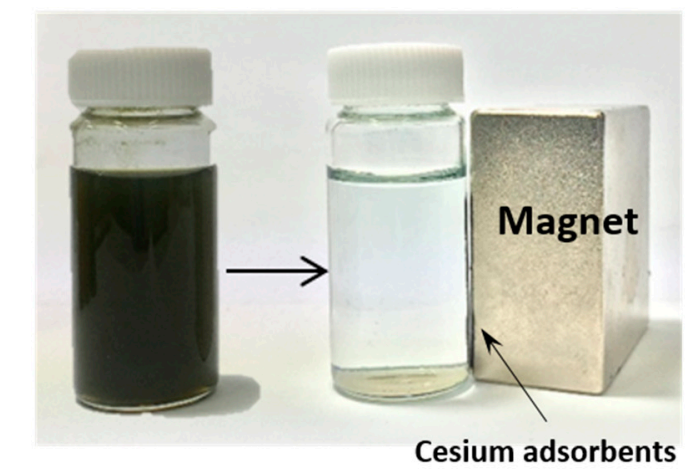

(b)

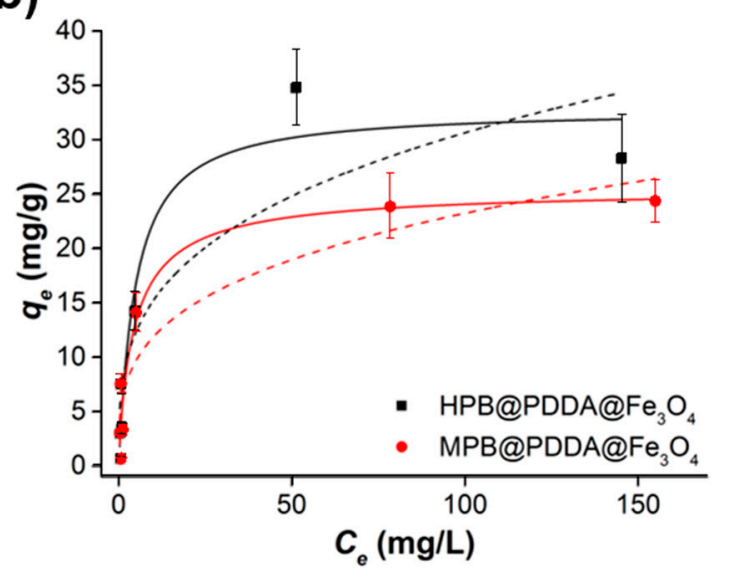

Figure 5. (a) Photograph shows the recovery of the composite with an external magnet after Cs adsorption; (b) nonlinear Langmuir (solid lines) and Freundlich (dotted lines) isotherm models.

\subsection{Radioactive Cesium Adsorption Studies}

Figure 6a shows the efficiency of adsorbents for the removal of ${ }^{137} \mathrm{Cs}$ from an aqueous solution using different adsorbent concentrations $(0.05,0.2$, and $0.5 \mathrm{mg} / \mathrm{mL})$. The initial ${ }^{137} \mathrm{Cs}$ concentrations were $92.38 \mathrm{~Bq} / \mathrm{g}$ and $86.44 \mathrm{~Bq} / \mathrm{g}$ for MPB- and HPB-coated nanoparticles, respectively. For a MPB@PDDA@ $\mathrm{Fe}_{3} \mathrm{O}_{4}$ composite, the removal of ${ }^{137} \mathrm{Cs}$ from the solution per gram of adsorbent was increased from $95.17 \%$ to $97.77 \%$ when increasing the adsorbent concentration from 0.05 to $0.5 \mathrm{mg} / \mathrm{mL}$. 
In the case of the HPB@PDDA@ $\mathrm{Fe}_{3} \mathrm{O}_{4}$ composite, the removal efficiency increased from 96.18\% to $99.69 \%$ with an increase in adsorbent concentration. This higher removal efficiency probably results from the higher surface area of the $\mathrm{HPB} @ P D D A @ \mathrm{Fe}_{3} \mathrm{O}_{4}$ compared to the $\mathrm{MPB} @ \mathrm{PDDA} @ \mathrm{Fe}_{3} \mathrm{O}_{4}$. The effect of $\mathrm{pH}$ on ${ }^{137} \mathrm{Cs}$ uptake by the HPB@PDDA@ $\mathrm{Fe}_{3} \mathrm{O}_{4}$ composite was investigated, as shown in Figure 6b. At the three $\mathrm{pH}$ values investigated (pH 4, 7, and 10), the HPB@PDDA@ $\mathrm{Fe}_{3} \mathrm{O}_{4}$ adsorbent removed over $92 \%$ of ${ }^{137} \mathrm{Cs}$, and a maximum ${ }^{137} \mathrm{C}$ s uptake of $98.26 \%$ was achieved at $\mathrm{pH}$. When the $\mathrm{pH}$ further increases or decreases, the adsorption sites become available for cation or anion in ion exchange processes, which leads to difficult cesium adsorption. Even though the removal efficiency of cesium ions is feasible across a wide range of $\mathrm{pH}$ values, the best results are achieved at neutrality.

The distribution coefficient $\left(K_{d}\right)$ was defined to analyze the cesium removal ability and adsorption performance of $\mathrm{HPB} @ P D D A @ \mathrm{Fe}_{3} \mathrm{O}_{4}$ toward ${ }^{137} \mathrm{Cs}$ :

$$
K_{d}=\frac{C_{0}-C_{f}}{C_{f}} \times \frac{V}{M}
$$

where $C_{0}$ and $C_{f}$ are the initial and final concentrations of $C s$ in the solution before and after equilibrium contact with the adsorbent, $\mathrm{V}$ is the volume of the solution, and $\mathrm{M}$ is the mass of the adsorbent used. For the HPB@PDDA@ $\mathrm{Fe}_{3} \mathrm{O}_{4}$ composite, the $K_{d}$ was calculated as $\sim 6.4 \times 10^{5} \mathrm{~mL} / \mathrm{g}$, which was an order of magnitude higher than the literature value for the PB adsorbent of $5.2 \times 10^{4} \mathrm{~mL} / \mathrm{g}$ [7]. Based on these results, we speculate that the resulting hollow adsorbents provide a wider reaction space through which cesium can be adsorbed, thereby increasing the adsorption capacity.

(a)

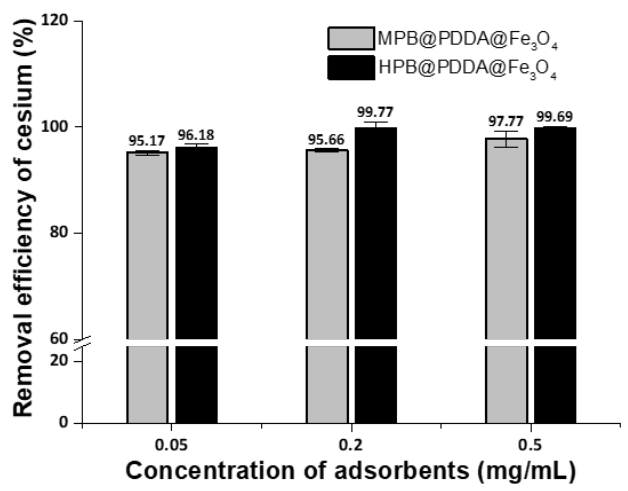

(b)

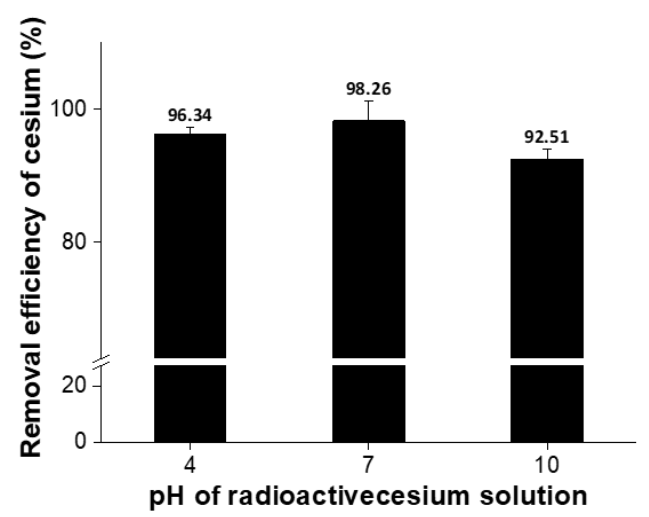

Figure 6. (a) Removal efficiency of ${ }^{137} \mathrm{Cs}$ by MPB@PDDA@ $\mathrm{Fe}_{3} \mathrm{O}_{4}$ and $\mathrm{HPB} @ P D D A @ \mathrm{Fe}_{3} \mathrm{O}_{4}$ composites and (b) influence of $\mathrm{pH}$ on the uptake of ${ }^{137} \mathrm{Cs}$ by $\mathrm{HPB} @ P D D A @ \mathrm{Fe}_{3} \mathrm{O}_{4}$ composite.

\section{Conclusions}

In this study, we successfully synthesized a new adsorbent material that shows a high cesium adsorption efficiency and easy recovery of adsorbents by decorating hollow PB onto a magnetic PDDA@ $\mathrm{Fe}_{3} \mathrm{O}_{4}$ composite. The hollow PB attached to the outside of the magnetic particles-like a bunch of grapes - can increase the active specific area and consequently improve the cesium adsorption capacity. Furthermore, the excellent magnetic composite property makes it possible to recover the adsorbent effectively and selectively bind cesium from contaminated radioactive wastewater through a magnetic field. In the selective adsorption experiment, the adsorbent, HPB@PDDA@Fe $\mathrm{O}_{4}$, exhibited an excellent maximum adsorption capacity of $32.8 \mathrm{mg} / \mathrm{g}$ and ${ }^{137} \mathrm{C}$ removal efficiency of $99.69 \%$. This new approach for the synthesis of a functional adsorbent can be an important contribution towards the effective removal of ${ }^{137} \mathrm{Cs}$. 
Supplementary Materials: The following are available online at http:/ / www.mdpi.com/1996-1944/11/6/998/s1. Figure S1: $(\mathrm{a}-\mathrm{c}) \mathrm{TEM}$ images of $\mathrm{Fe} 3 \mathrm{O} 4$ nanoparticles, Figure S2: (a) TEM image of MPB and (b) magnified image. (c) TEM image of HPB and (d) magnified image, Figure S3: XRD patterns of Fe3O4 nanoparticles.

Author Contributions: S.-C.J., S.-M.K., G.Y.K., and Y.S.H. conceived the idea, designed the research, performed the experiments, and analyzed the data. S.-C.J., Y.H., M.R., C.R., J.C.R., and Y.S.H. wrote the main manuscript. G.Y.K. and I.L. assisted in experiments. Y.-K.H. and J.C.R. supported the interpretation of results. J.C.R., C.R., and Y.S.H. supervised the research. All authors including M.R. discussed the results and reviewed the manuscript.

Acknowledgments: This work was supported by the Radiation Fusion Technology Program (2015M2A2A6A02045262(3)) from Nuclear Research R\&D Program through the National Research Foundation of Korea (NRF) funded by the Ministry of Science, ICT \& Future Planning (MSIP), Republic of Korea. And, this article will support a collaborative joint research call in Korea-UK on nuclear decommissioning/nuclear waste treatment and disposal for deeper and larger collaborations in the future.

Conflicts of Interest: The authors declare no conflict of interest.

\section{References}

1. Buesseler, K.O.; Jayne, S.R.; Fisher, N.S.; Rypina, I.I.; Baumann, H.; Baumann, Z.; Breier, C.F.; Douglass, E.M.; George, J.; Macdonald, A.M. Fukushima-derived radionuclides in the ocean and biota off Japan. Proc. Natl. Acad. Sci. USA 2012, 109, 5984-5988. [CrossRef] [PubMed]

2. Tsuji, H.; Yasutaka, T.; Kawabe, Y.; Onishi, T.; Komai, T. Distribution of dissolved and particulate radiocesium concentrations along rivers and the relations between radiocesium concentration and deposition after the nuclear power plant accident in Fukushima. Water Res. 2014, 60, 15-27. [CrossRef] [PubMed]

3. Hayano, R.S.; Tsubokura, M.; Miyazaki, M.; Satou, H.; Sato, K.; Masaki, S.; Sakuma, Y. Comprehensive whole-body counter surveys of Miharu-town school children for three consecutive years after the Fukushima NPP accident. Proc. Jpn. Acad. Ser. B Phys. Biol. Sci. 2014, 90, 211-213. [CrossRef] [PubMed]

4. Montaña, M.; Camacho, A.; Devesa, R.; Vallés, I.; Céspedes, R.; Serrano, I.; Blázquez, S.; Barjola, V. The presence of radionuclides in wastewater treatment plants in Spain and their effect on human health. J. Clean. Prod. 2013, 60, 77-82. [CrossRef]

5. Steinhauser, G.; Schauer, V.; Shozugawa, K. Concentration of strontium-90 at selected hot spots in Japan. PLoS ONE 2013, 8, e57760. [CrossRef] [PubMed]

6. Leppänen, A.-P.; Mattila, A.; Kettunen, M.; Kontro, R. Artificial radionuclides in surface air in Finland following the Fukushima dai-ichi nuclear power plant accident. J. Environ. Radioact. 2013, 126, $273-283$. [CrossRef] [PubMed]

7. Sangvanich, T.; Sukwarotwat, V.; Wiacek, R.J.; Grudzien, R.M.; Fryxell, G.E.; Addleman, R.S.; Timchalk, C.; Yantasee, W. Selective capture of cesium and thallium from natural waters and simulated wastes with copper ferrocyanide functionalized mesoporous silica. J. Hazard. Mater. 2010, 182, 225-231. [CrossRef] [PubMed]

8. García, O.; Mandina, T. DNA damage evaluated by the comet assay in lymphocytes of children with ${ }^{137} \mathrm{Cs}$ internal contamination caused by the Chernobyl accident. Mutat. Res. Genet. Toxicol. Environ. Mutagen. 2005, 565, 191-197. [CrossRef] [PubMed]

9. Heidenreich, W.F.; Cullings, H. Use of the individual data of the a-bomb survivors for biologically based cancer models. Radiat. Environ. Biophys. 2010, 49, 39-46. [CrossRef] [PubMed]

10. Jordan, B. Surprising results from Hiroshima studies. Med. Sci. 2014, 30, 211-213.

11. Vasilenko, I. The biological action of nuclear fission products. Their metabolism and acute lesions. Radiobiologiia 1992, 32, 69-78. [PubMed]

12. Gupta, R.; Dubey, S. Removal of cesium ions from aqueous solution by polyaniline: A radiotracer study. J. Polym. Res. 2005, 12, 31-35. [CrossRef]

13. Lee, K.-Y.; Park, M.; Kim, J.; Oh, M.; Lee, E.-H.; Kim, K.-W.; Chung, D.-Y.; Moon, J.-K. Equilibrium, kinetic and thermodynamic study of cesium adsorption onto nanocrystalline mordenite from high-salt solution. Chemosphere 2016, 150, 765-771. [CrossRef] [PubMed]

14. Thammawong, C.; Opaprakasit, P.; Tangboriboonrat, P.; Sreearunothai, P. Prussian blue-coated magnetic nanoparticles for removal of cesium from contaminated environment. J. Nanopart. Res. 2013, 15, 1689. [CrossRef] 
15. Faustino, P.J.; Yang, Y.; Progar, J.J.; Brownell, C.R.; Sadrieh, N.; May, J.C.; Leutzinger, E.; Place, D.A.; Duffy, E.P.; Houn, F. Quantitative determination of cesium binding to ferric hexacyanoferrate: Prussian blue. J. Pharm. Biomed. Anal. 2008, 47, 114-125. [CrossRef] [PubMed]

16. Jang, S.-C.; Haldorai, Y.; Lee, G.-W.; Hwang, S.-K.; Han, Y.-K.; Roh, C.; Huh, Y.S. Porous three-dimensional graphene foam/prussian blue composite for efficient removal of radioactive ${ }^{137}$ Cs. Sci. Rep. 2015, 5, 17510. [CrossRef] [PubMed]

17. Qian, J.; Ma, J.; He, W.; Hua, D. Facile synthesis of Prussian blue derivate-modified mesoporous material via photoinitiated thiol-ene click reaction for cesium adsorption. Chem. Asian J. 2015, 10, 1738-1744. [CrossRef] [PubMed]

18. Delchet, C.; Tokarev, A.; Dumail, X.; Toquer, G.; Barré, Y.; Guari, Y.; Guerin, C.; Larionova, J.; Grandjean, A. Extraction of radioactive cesium using innovative functionalized porous materials. RSC Adv. 2012, 2, 5707-5716. [CrossRef]

19. Jang, S.-C.; Kang, S.-M.; Haldorai, Y.; Giribabu, K.; Lee, G.-W.; Lee, Y.-C.; Hyun, M.S.; Han, Y.-K.; Roh, C.; Huh, Y.S. Synergistically strengthened $3 \mathrm{~d}$ micro-scavenger cage adsorbent for selective removal of radioactive cesium. Sci. Rep. 2016, 6, 38384. [CrossRef] [PubMed]

20. Jang, S.-C.; Hong, S.-B.; Yang, H.-M.; Lee, K.-W.; Moon, J.-K.; Seo, B.-K.; Huh, Y.S.; Roh, C. Removal of radioactive cesium using prussian blue magnetic nanoparticles. Nanomaterials 2014, 4, 894-901. [CrossRef] [PubMed]

21. Hu, M.; Furukawa, S.; Ohtani, R.; Sukegawa, H.; Nemoto, Y.; Reboul, J.; Kitagawa, S.; Yamauchi, Y. Synthesis of Prussian blue nanoparticles with a hollow interior by controlled chemical etching. Angew. Chem. 2012, 124, 1008-1012. [CrossRef]

22. Arun, T.; Prakash, K.; Kuppusamy, R.; Joseyphus, R.J. Magnetic properties of Prussian blue modified $\mathrm{Fe}_{3} \mathrm{O}_{4}$ nanocubes. J. Phys. Chem. Solids 2013, 74, 1761-1768. [CrossRef]

23. Zhang, W.; Wu, L.; Du, L.; Yue, L.; Guan, R.; Zhang, Q.; Hou, G.; Shao, R. Layer-by-layer assembly modification to prepare firmly bonded $\mathrm{Si}$-graphene composites for high-performance anodes. RSC Adv. 2016, 6, 4835-4842. [CrossRef]

24. Langmuir, I. The adsorption of gases on plane surfaces of glass, mica and platinum. J. Am. Chem. Soc. 1918, 40, 1361-1403. [CrossRef]

25. Freundlich, H. Over the adsorption in solution. J. Phys. Chem. 1906, 57, 385-470. 